\title{
Abbreviations of Film Titles
}

DCH Dil Chahta Hai (200I)

DDLF Dilmale Dulhaniya Le Fayenge (1995)

E.T. E.T.: The Extra Terrestrial (1982)

KANK Kabhi Alvida Naa Kehna (2006)

$K_{3} G \quad$ Kabhi Kushi Kabhie Gham (200I)

$\mathrm{KHNH}$ KalHo Naa Ho (2003)

KMG Koi... Mil Gaya (2003)

$\mathrm{K}_{2} \mathrm{H}_{2} \quad$ Kuch Kuch Hota Hai (1998)

MNIK My Name Is Khan (2013)

OSO Om Shanti Om (2007) 